\title{
Regular physical exercise in patients with type II diabetes mellitus
}

\author{
C. Nakhanakhup • P. Moungmee • H. J. Appell • \\ J. A. Duarte
}

Published online: 6 April 2006

(C) EGREPA 2006

\begin{abstract}
It is widely accepted that regular physical exercise helps diabetic patients control blood glucose, reduce cardiovascular risk factors, and prevent other related complications. In spite of the undoubted benefits of regular physical exercise, diabetic patients with chronic complications should be aware of potential hazards of practicing exercise. To avoid some harmful consequences of acute exercise, it is necessary to adopt a vigilant attitude with these risk patients and to carefully adjust type and intensity of exercise to the individual situation. This article intends to summarize and analyze the current literature concerning the preventive and therapeutic effects of regular exercise in diabetic patients, pointing out its physiological influence on blood glucose regulation, and to analyze the potential risks of acute physical exercise and the precautions given to patients with a variety of complications.
\end{abstract}

Keywords Physical activity · Diabetes mellitus · Diabetic chronic complications - Patient management . Safety exercise

C. Nakhanakhup · P. Moungmee

College of Sport Science, Burapha University,

Chonburi, 20131, Thailand

H. J. Appell

Department of Physiology and Anatomy,

German Sports University,

Cologne, Germany

C. Nakhanakhup $(\varangle) \cdot$ J. A. Duarte

CIAFEL, Faculty of Sports,

R. Dr. Plácido Costa, 91,

4200-450, Porto, Portugal

e-mail: chirapa_n@hotmail.com

\section{Introduction}

Diabetes mellitus (DM) constitutes one of the most widespread health problems in the world, as it is estimated that its prevalence of 171 million observed in 2000 will increase to 366 million in the year 2030 [50]. The interactions of environmental and behavioral factors, such as physical inactivity, obesity, and stress, with genetic factors seem to be the main reason for the epidemic character of DM [17, 32]. These factors are responsible for the alteration in glucose homeostasis by impaired glucose tolerance, which can result from pancreatic $\beta$ cell dysfunction and/or from the increase of insulin resistance in target tissues [17, 32]. Eightyfive to $95 \%$ of all DM cases are characterized by glucose intolerance induced by insulin resistance $[5,17$, 33]. Independent of its origin, the resultant chronic hyperglycemia may negatively influence the structure and function of many organs, particularly the cardiovascular, nervous, and renal systems [33]. Heart disease is the prevailing cause of diabetes-related deaths, and it could be expected that approximately $50 \%$ of all diabetic patients evidencing signs of nervous system impairment are affected by cardiac autonomic neuropathy [3, 6, 17, 34].

Exercise is one of the main therapeutic measures to deal with high blood glucose levels in diabetic patients $[8,15,25,28]$. It is believed to control hyperglycemia through the improvement of peripheral insulin sensitivity particularly in skeletal muscle [22, 38]. In addition, many studies have also described exercise as a countermeasure against many abnormalities observed in diabetic patients, such as hyperlipidemia, hypertension, and a tendency for hypercoagulation [7, $10,47]$, which are considered to increase the risk of 
Table 1 Criteria to check for the existence of type II DM in adults (adapted from the American Diabetes Association [8])

1. Subjects aged more than 45 years

(When normal, the checkup should be repeated every 1-3 years)

2. Occurrence of symptoms like polyuria, polydipsia, and unexplained weight loss

3. Asymptomatic subjects carrying at least one of the following risk factors:

3.1. Have a first-degree parent with diabetes

3.2. Overweight or with a BMI $>25 \mathrm{~kg} / \mathrm{m}^{2}$

3.3. History of impaired glucose tolerance or impaired fasting glucose in a previous test

3.4. Hypertension (>140/90 $\mathrm{mmHg}$ )

3.5. A plasma high density lipoprotein cholesterol level $<35 \mathrm{mg} /$ $\mathrm{dl}$ and/or a plasmatic triglyceride level $>250 \mathrm{mg} / \mathrm{dl}$

3.6. History of gestational DM or of a newborn child weighing more than $4.08 \mathrm{~kg}$

3.7. Sedentary lifestyle

3.8. Other clinical conditions associated with insulin resistance, such as polycystic ovary syndrome and acanthosis nigricans

macro- and microvascular complications [21, 46]. These and many other chronic complications of diabetes mellitus seem to be attenuated by the regular practice of physical exercise.

\section{Etiological classification and diagnostic criteria of DM}

$\mathrm{DM}$ is the general designation for a collection of endocrine disorders with different kinds of pathogenesis. The American Diabetes Association and the World Health Organization (WHO) identified new classification criteria of diabetes mellitus in 1997. This classification includes four clinical categories named "type I DM," "type II DM," "other specific types of DM," and "gestational DM" [30].

Type I diabetes mellitus (also known as insulindependent diabetes mellitus or juvenile diabetes) mainly results from the destruction of beta cells in the pancreatic Langerhans' islets, leading to an insulin deficiency; the onset of this type is usually at younger ages and normally requires insulin supplementation $[30,32]$. Type II diabetes mellitus (also known as noninsulin-dependent diabetes mellitus) could be the result of inadequate insulin secretion, insulin resistance in peripheral tissues, or excessive hepatic glucose production [16, 30, 32], which impair glucose tolerance (hyperglycemia); this variant usually occurs in individuals aged more than 40 years with a family history of $\mathrm{DM}$, and apart from the genetic predisposition, the occurrence of this type of disease is correlated with physical inactivity and being overweight $[5,16,17,32]$. The category "other specific types of DM" consists of all particular cases of disease where genetic defects are responsible for beta cell dysfunction (maturity onset diabetes in youth) or for insulin resistance in target tissues, and of all DM situations resulting from endocrinological pathologies or pancreatic dysfunction induced by drugs/toxics or infections [5]. Gestational diabetes mellitus occurs during pregnancy and is the result of a relative insulin deficiency at the last stage of pregnancy [5].

Patients with type I DM exhibit normal symptoms and represent about 5 to $10 \%$ of all cases of DM; on the other hand, type II DM constitutes the most prevalent category of the disease $(90 \%-95 \%)$ and often remains undiagnosed until complications become symptomatic [5]. Thus, particularly in patients with type II DM, early detection of the disease allows them to make lifestyle changes and initiate medical therapy, which can reduce the appearance of complications. Considering the higher and constantly increasing prevalence of type II DM and the great potential of nonpharmacological measures associated with small modifications in lifestyle for primary and secondary disease prevention, the medical community has granted much attention to this type of DM and has defined a set of rules for early diagnosis of the disease. Tests to detect the occurrence of type II DM should always be considered in subjects who have one or more of the risk factors for the development of the disease, as shown in Table 1 [8].

Table 2 The WHO criteria for DM diagnosis (adapted from Mayfield [30])

\begin{tabular}{|c|c|c|c|c|c|c|}
\hline & \multicolumn{2}{|c|}{ Fasting plasma glucose } & \multicolumn{2}{|c|}{ Plasma glucose $2 \mathrm{~h}$ after beginning OGTT } & \multicolumn{2}{|c|}{ Casual plasma glucose } \\
\hline & $\mathrm{mg} / \mathrm{dl}$ & $\mathrm{mmol} / \mathrm{l}$ & $\mathrm{mg} / \mathrm{dl}$ & $\mathrm{mmol} / \mathrm{l}$ & $\mathrm{mg} / \mathrm{dl}$ & $\mathrm{mmol} / \mathrm{l}$ \\
\hline Normal & $<110$ & $<6.1$ & $<140$ & $<7.75$ & & \\
\hline IFG & $\geq 110<126$ & $\geq 6.1<7.0$ & & & & \\
\hline IGT & & & $\geq 140<200$ & $\geq 7.75<11.1$ & & \\
\hline DM & $\geq 126$ & $\geq 7$ & $\geq 200$ & $\geq 11.1$ & $>200$ & $>11.1$ \\
\hline
\end{tabular}

IFG Impaired fasting glucose, IGT impaired glucose tolerance, $D M$ diabetes mellitus, $O G T T$ oral glucose tolerance test

Causal plasma glucose is defined as the glucose levels measured anytime of the day, regardless of the time passed after the last meal 


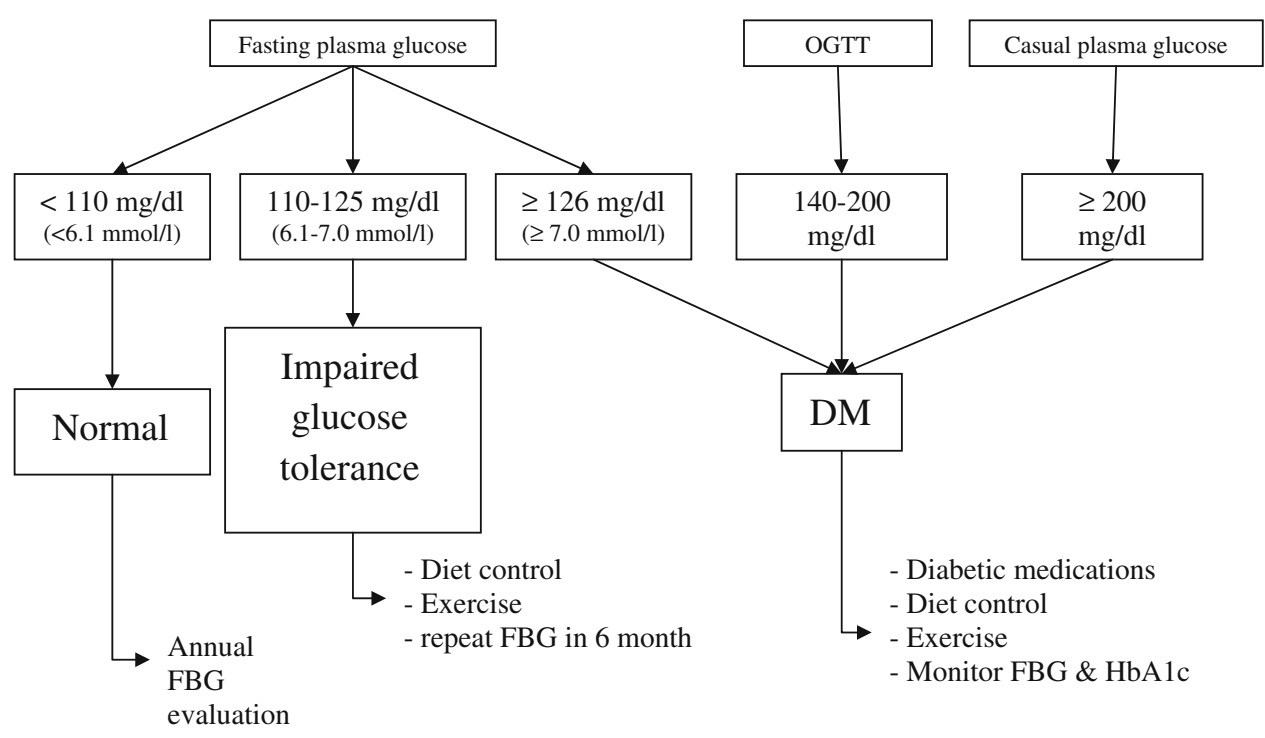

Fig. 1 Guidelines for diagnosis and blood glucose control in type II diabetes mellitus (adapted from Mayfield [30])

According to the WHO recommendations (see Table 2), a positive outcome in two of the following tests to be carried out on different days, constitutes the criteria for diabetes mellitus diagnosis (Fig. 1) [30]: (1) the existence of suspected symptoms of DM and the occurrence of plasma glucose levels higher than 200 $\mathrm{mg} / \mathrm{dl}$ ( or $11.1 \mathrm{mmol} / \mathrm{l}$ ), measured any time of the day regardless of the time that passed after the last meal; (2) the occurrence of a fasting plasma glucose level higher than $126 \mathrm{mg} / \mathrm{dl}$ (or $7.0 \mathrm{mmol} / \mathrm{l}$ ); and (3) a plasma glucose level higher than $200 \mathrm{mg} / \mathrm{dl}$ (or $11.1 \mathrm{mmol} / \mathrm{l}$ ) 2 $\mathrm{h}$ after beginning an oral glucose tolerance test (OGTT). OGTT is recommended when fasting plasma glucose levels are between 5.5 and $7.7 \mathrm{mmol} / \mathrm{l}$.

The condition of impaired glucose tolerance (IGT) is defined when fasting plasma glucose levels are higher than normal levels but too low to reach the criteria for DM diagnosis.

\section{Management of type II DM patients}

The goal of DM treatment is directed toward glycemic control, the correction of all metabolic and functional abnormalities such as dyslipidemia, hypertension, and obesity, and the control of morbidity and mortality related with the disease [8]. Apart from medication, the standard therapeutic procedures for the treatment of type II DM include correct dietary control and regular exercise $[8,9,25,35]$. According to these authors, the management of each patient should be individualized and adjusted to age, medical history, earlier physical activity, eating habits, and sociocultural factors. Especially before starting an exercise program, a medical examination is necessary to detect other diseases or diabetic complications that might represent contraindications.

\section{Glycemic control}

Glycemic control is a main objective in DM patients. Several studies have shown that improved glycemic control is associated with decreased rates of chronic complications, such as retinopathy, nephropathy, neuropathy, and cardiovascular diseases [19, 41, 43, 44].

Capillary blood glucose monitored by the patient himself represents a useful procedure to control glycemia and to adjust medications or physical activity/exercise prescriptions. Usually, capillary blood glucose monitored once a day is important for the patient to check to prevent asymptomatic hypoglycemia. Glycated hemoglobin (HbA1c) is required to estimate the mean glycemia over the preceding 2-3 months and must be measured at least twice a year to determine whether metabolic control is maintained within a normal range [39]. Thus, HbA1c is useful in assessing treatment efficiency and in comparing the result of the patient's self-reported testing (Table 3).

Table 3 Parameters used for a glycemic control in type II DM patients (adapted from the American Diabetes Association [8])

\begin{tabular}{cll}
\hline Blood samples & $\begin{array}{l}\text { Glucose plasma } \\
\text { concentrations }\end{array}$ & $\begin{array}{l}\text { Hemoglobin A1c } \\
\text { plasma levels }\end{array}$ \\
\hline Fasting & $\begin{array}{l}90-130 \mathrm{mg} / \mathrm{dl} \\
\text { condition }\end{array}$ & $<7.0 \%-7.2 \mathrm{mmol} / \mathrm{l})$ \\
Postprandial & $<180 \mathrm{mg} / \mathrm{dl}$ & \\
peak level & $(<10.0 \mathrm{mmol} / \mathrm{l})$ & \\
\hline
\end{tabular}


Health education

Bodyweight less than $120 \%$ of the ideal bodyweight for normal people is recommended for DM and the main goals of medical nutrition therapy for this disease are the following [8]: (1) to attain and maintain metabolic control, stabilizing blood glucose level in the normal or nearly normal range; (2) to prevent or reduce complications of diabetes related to the lipid and lipoprotein profile, which reduces the risk for macrovascular disease; (3) to prevent and treat chronic complications of diabetes; and (4) to improve health through appropriate choice of food, taking into account personal and cultural preferences.

Diabetic patients should consume between 2,000 and 2,500 calories/day to maintain ideal bodyweight [28]. Carbohydrates and monosaturated fat should provide approximately $60-70 \%$ of energy intake. Carbohydrates from whole grains, fruits, vegetables, and low-fat milk should be included in the diet. Some carbohydrates such as candy and cookies should be avoided because they induce a rapid rise in blood glucose. The average amount of carbohydrates recommended for patients with DM is 40 to $60 \%$ of dietary intake $[1,17]$. However, several studies suggest that the replacement of monosaturated fat by carbohydrates can reduce postprandial glycemia and triglyceridemia in type II DM patients [20]. Starch with fiber may slow down glucose absorption. Nonnutritive sweeteners (low caloric sugar) are safe for diabetic patients when consumed within the acceptable daily intake level established by the US Food and Drug Administration [18]. The maximum acceptable daily intake of aspartame, acesulfame $\mathrm{K}$, and sucralose are, $50 \mathrm{mg} / \mathrm{kg}, 15 \mathrm{mg} / \mathrm{kg}$, and $5 \mathrm{mg} / \mathrm{kg}$, respectively [18]. The protein intake of diabetic patients should sustain $15-20 \%$ of the total daily energy spent, and at the moment, there is no evidence suggesting that protein intake should be modified in patients with normal renal function. It is assumed that $10 \%$ of energy intake should be derived from fats and cholesterol intake, constituting approximately $300 \mathrm{mg} /$ day [4].

\section{Physical exercise in diabetic patients}

Important sources of energy for living organisms are carbohydrates and especially glucose, and low blood glucose can cause loss of consciousness, seizures, and death. On the other hand, chronically elevated concentrations in blood glucose can result in blindness, renal failure, cardiac and peripheral vascular diseases, and neuropathy [17]. Therefore, blood glucose con- centrations should be maintained within narrow limits to prevent complications. During fasting, the physiological blood concentrations of glucose are maintained by the liver. In the postprandial state, the rise in blood glucose concentration stimulates insulin secretion, which reduces hepatic glucose production and increases membrane glucose transporters (GLUT) in peripheral tissues, thus reducing blood glucose $[11,13$, 24, 26].

During exercise, and compared to the basal status, recruited skeletal muscles require four- to fivefold more energy for contraction, using blood glucose, muscle glycogen, and fatty acids derived from adipose tissue as metabolic fuel [37]. Muscle glycogen serves as the main fuel source during strenuous and short-term exercise in healthy subjects. When the duration of exercise is prolonged, muscle energy is predominantly derived from blood-born glucose and from fatty acids produced in the adipose tissue [37, 49, 52]. Enhanced plasma levels of adrenalin, glucagon, cortisol, and growth hormone promote both an increased glucose production and a mobilization of fatty acid from adipose tissue [37, 49, 52]. In addition, gluconeogenesis maintains glucose homeostasis by synthesizing glucose from substrates like pyruvate. These changes may increase fuel supply to the skeletal muscle contraction during exercise and prevent hypoglycemia as a result of excessive utilization of glucose by the contracting muscles.

Physical exercise is a recommended treatment for patients with type II DM because it enhances the GLUT4 expression in trained skeletal muscle with a consequent increase in the glucose transport capacity [48]. This mechanism may explain the enhanced sensitivity to insulin observed in physically active DM patients $[11,13,16,22,24,26]$. Increased mass in skeletal muscle, enhanced blood flow in muscle, greater density of insulin receptors, enhanced disposal of glucose in skeletal muscle, and a reduction in body fat could also contribute to this insulin sensitivity and improved glucose tolerance induced by physical training in DM patients [25, 49].

As mentioned above, the aim of exercise in type II diabetic patients is to induce acute and chronic physiological changes, which improve insulin sensitivity and glucose tolerance [11, 13, 22, 23, 24, 26]. To maintain glucose homeostasis, glucagon and adrenalin are released during acute exercise, which increases hepatic glucose production; simultaneously, the insulin secretion by pancreatic $\beta$ cells is reduced $[37,40,52]$. Thus, an increase in glucose utilization during acute exercise is accompanied by an increase in hepatic glucose production, an improved insulin sensitivity 
enhancing the binding of insulin to sarcolemmal receptors, and an increased GLUT4 expression [15]. From a chronic perspective, the improvement in insulin sensitivity is positively correlated with the intensity of aerobic endurance training, which is in accordance with the fact that insulin resistance in type II diabetic patients is associated with diminished physical fitness [15]. Regular exercise, combined with dietary control training, leads to changes in body composition, namely, a reduction in body fat and an increase in muscle mass $[9,15]$. This association of dietary control with physical training seems to improve the glycemic control better than exercise alone [9, 15], and this assumption offers an explanation to why obese subjects with type II DM, when compared to non-obese patients, show no beneficial effects in insulin sensitivity from training alone [36].

When patients with type II DM participate in physical training programs, metabolic control is improved, as evidenced for example by a decrease in serum triglyceride (TG) and very low density lipoprotein (VLDL) cholesterol and an increase in high density lipoprotein cholesterol at rest [2]. However, some studies have found that middle-aged subjects (age 4054 years) who exercise regularly have a better response in metabolic control when compared to older subjects (age 57-61 years), perhaps due to different pretraining levels of metabolic control or to differences in the intensity of the training program or magnitude of chronic complications with advanced age [48].

\section{Precautions before starting a training program}

Before starting an exercise program, patients should submit to a medical examination. Because these patients have an increased risk of coronary artery disease and silent cardiac ischemia, the examination should screen the presence of macro- and microvascular complications that may be worsened during acute exercise [2, 17, 19, 34, 40, 48]. In general, physical exercise could be safely performed by patients with good glycemic control and without any manifested chronic complications [8]. However, before starting any training program, a laboratory-graded exercise test is recommended for all diabetic patients over 35 years $[7,8]$ and must be performed in high-risk cardiovascular patients based on one of the following criteria [5, 7]: (1) age $\geq 35$ years or age $\geq 25$ years with a history of type II DM diagnosed more than 10 years earlier, (2) presence of any additional risk factors for coronary artery disease, (3) presence of microvascular diseases (retinopathy, nephropathy, microalbuminuria), peripheral vascular disease, or autonomic neuropathy.
Table 4 Summary of preexercise blood glucose values (adapted from Leutholtz and Ripoll [28])

\begin{tabular}{ll}
\hline $\begin{array}{l}\text { Blood glucose } \\
\text { levels }(\mathrm{mg} / \mathrm{dl})\end{array}$ & Recommendations \\
\hline$>300$ & $\begin{array}{l}\text { Do not exercise on that day } \\
\text { Exercise must be done with caution; if } \\
\text { blood glucose rises after 10 min of } \\
\text { exercise, exercise must be stopped. }\end{array}$ \\
$\begin{array}{l}\text { Safe levels for exercise } \\
\text { Be alert for signs and symptoms of } \\
\text { hypoglycemia. }\end{array}$ \\
$\begin{array}{l}\text { No exercise } \\
<100\end{array}$
\end{tabular}

Moreover, this test is used to define exercise intensity, duration, and frequency as well as other modalities of the training program.

The monitoring of blood glucose concentration before, during, and after any acute exercise is considered a necessary procedure to prevent unpleasant situations (Table 4). Blood glucose ranging from 150$249 \mathrm{mg} / \mathrm{dl}$ is considered a safe amount for practicing exercise [7, 28]. If these levels exceed $250 \mathrm{mg} / \mathrm{dl}$, exercise is contraindicated. Immediately after exercise, patients should monitor blood glucose to prevent low concentrations (lower than $70 \mathrm{mg} / \mathrm{dl}$ ). In fact, one of the most common causes of low blood glucose is the exaggerated practice of physical activity. To prevent low blood glucose or even hypoglycemia, diabetic patients should avoid hot environments, like saunas or steam rooms immediately after exercise, as these favor the maintenance of an increased metabolic rate and may be responsible for lower blood glucose. Patients should also avoid the consumption of alcohol before or immediately after exercise, as well as exercising at the peak of insulin action [12]. Although exercise-induced hypoglycemia is a less common problem in type II DM than in type I DM, the risk is increased in patients who are using insulin [15]. Changes in dosage or in the timing of insulin administration, as well as modifications, in meal habits are usually efficient procedures to correct the problem.

A standard recommendation of the American Diabetes Association and the American College of Sports Medicine for diabetic patients includes a warm up and a cool down period that should consist of 5-10 min of aerobic activity at low intensity, as well as a stretching period [7]. The aim of the warm up session is to prepare skeletal muscle and the cardiovascular and respiratory systems for a progressive increase in exercise intensity, and the cool down period allows a gradual adjustment to baseline of heart rate and blood pressure [7]. Stretching should be performed for 5-10 
min, especially in muscles used during the training session. It is important for DM patients to prevent foot blisters by use of adequate socks and appropriate shoes; any potential damage to their feet must be monitored before and after any exercise session. Because dehydration can affect blood glucose levels and cardiovascular function, it is recommended to ingest $500 \mathrm{ml}$ of fluid until $2 \mathrm{~h}$ before starting the exercise. During exercise, the fluid ingestion should compensate all losses taking place by sweat and ventilation, to avoid a loss of bodyweight at the end of acute exercise [7].

\section{Exercise recommendation for type II diabetic patients}

Exercise programs for diabetic patients should consist of aerobic endurance exercise, which enhances cardiorespiratory fitness, muscular strength, and endurance, and modifies body composition. However, in patients with type II DM, this type of training together with resistance training, as opposed to aerobic training alone, seems to induce better positive adaptations of glucose control, insulin function, muscular strength, and exercise tolerance [29, 42]. Nevertheless, resistance exercise or exercise performed at high intensities should only be carried out by individuals without any DM-associated chronic complications, such as proliferative retinopathy or hypertension $[2,7,14,40]$.

Table 5 describes the exercise components recommended for type II DM patients. To achieve cardiorespiratory and metabolic improvements, the exercise intensity must be individually adjusted from low to moderate, in correspondence to $40-70 \%$ of maximum oxygen consumption $[17,34,43]$. The use of heart rate for monitoring exercise intensity may not be suitable in patients with type II DM because they may develop autonomic neuropathy, which affects the heart rate response to exercise $[2,14,40]$. Intensity should rather be estimated using ratings of perceived exertion (RPE), with recommended RPE of 10-16 (very light to hard). The duration of exercise is directly related to the caloric expenditure required and is inversely related to the intensity. At least $30 \mathrm{~min}$ of continuous and moderate exercise should be performed in each training session. If weight loss is the main target of exercise, its intensity needs to be set from low to moderate $\left(50 \% \mathrm{VO}_{2} \max \right)$, and the duration needs to be increased up to $60 \mathrm{~min}$.

To improve cardiovascular performance, the recommended frequency of exercise is between three and five sessions per week. Moreover, obese diabetic patients may need to participate in daily physical activity to maximize caloric expenditure for effective weight management. Normally, patients with type II DM are elderly, showing a decline in muscle mass associated with a reduction in metabolic function. Resistance training programs increase muscle strength and muscle mass. Patients, however, with blood glucose higher than $300 \mathrm{mg} / \mathrm{dl}$, congestive heart failure, uncontrolled arrhythmias, severe valvular malfunction, or an aerobic capacity lower than five MET, are not allowed to perform this type of training $[14,15,34,40$, 52].

Resistance training should be performed at low intensity [ $40-50 \%$ of 1 repetition maximum (RM)], with 10-15 repetitions for each muscle group and a 3:1 ratio of endurance/resistance sessions [15, 28]. Low intensity is suggested to avoid exaggerated blood pressure. In the same way, regular breathing during exertion can also prevent a severe rise in cardiac afterload. The type of weightlifting equipment that could be used depends on the patients' preferences and abilities [28].

There are several safe forms of exercise such as walking, jogging, bicycling, and swimming, which allow patients to maximize their caloric expenditure and to improve physical fitness enjoyably and effectively. Long-term exercise programs are usually accompanied by a dropout rate of $90 \%$ of the initial participants after 1 year[15], while in short-term exercise programs, dropout rates range from $35-80 \%$ during the first 3-6

Table 5 Exercise characteristics recommended for type II DM patients (based on data from the American Diabetes Association [7], Eriksson [15], Leutholtz and Ripoll [28], and Peirce [34])

\begin{tabular}{|c|c|c|c|}
\hline Type & Duration & Frequency & Intensity \\
\hline $\begin{array}{l}\text { Aerobic exercise such as walking, } \\
\text { running, bicycling, swimming }\end{array}$ & $\begin{array}{l}\text { At least } 30 \mathrm{~min} / \mathrm{session} \\
\text { or } 150 \mathrm{~min} / \text { week } \\
90 \mathrm{~min} / \text { week }\end{array}$ & $\begin{array}{l}3-5 \text { days a } \\
\text { week }\end{array}$ & $\begin{array}{l}40-60 \% \mathrm{VO}_{2} \text { max or RPE } 10-16 \text { or } 50- \\
70 \% \text { of maximum heart rate } \\
>60 \% \mathrm{VO}_{2} \text { max or }>70 \% \text { of maximum } \\
\text { heart rate }\end{array}$ \\
\hline Resistance & 10-15 repetitions & 2 days a week & $40-50 \%$ of $1 \mathrm{RM}$ \\
\hline Warm up/cool down & $5-10 \mathrm{~min}$ & $\begin{array}{l}\text { Before and } \\
\text { after exercise }\end{array}$ & Low intensity \\
\hline
\end{tabular}


months [27]. Many reasons could contribute to refraining from maintenance of exercise, including lack of time, travel problems, expenses, and injury, but waning motivation seems to be the main cause [31]. Setting of personal goals for individuals is necessary, both for the DM patients and staff involved in the program, because both are equally important in providing encouragement to continue exercising. Even though participation in regular exercise programs may be low, a good strategy to maintain patients' involvement in such programs can be enhanced by routine activities of daily living. Lifestyle modifications such as stair climbing instead of using an elevator, household tasks, and gardening can provide appropriate physical activity with increased calorie burning [15].

\section{Exercise recommendations to patients with DM complications}

Type II DM is closely associated with obesity, dyslipidemia, and hypertension, which are important risk factors for micro- and macrovascular diseases. Concerning the prevalence of complications, at least $72 \%$ of patients have at least one complication; $19 \%$ only have a microvascular complication, such as neuropathy $(28 \%)$, renal damage $(20 \%)$, or retinopathy $(20 \%)$, and $10 \%$ of the patients have only a macrovascular complication, which could be peripheral vascular disease $(18 \%)$, angina $(17 \%)$, heart failure $(12 \%)$, and myocardial infarction (9\%) [33] (see Table 6). In people with DM, the persistently prolonged high blood-glucose concentration may cause peripheral neuropathy, which affects the limb nerves, which supply the muscles, vessels, and skin of the feet, legs, hands, and arms. The related symptoms may include numbness or loss of sensation, tingling, coldness, burning pain, hypersensitivity to touch, and problems in balance or coordination. One might therefore consider non-weight-bearing exercise in these cases. Because repetitive exercise on hyposensitive feet can lead to or aggravate an existent foot ulcer, the practice of weight-bearing exercise should be restricted. The use of well-fitted shoes and a daily foot examination are also important measures for preventing this kind of injury [7, 34, 40]. The occurrence of autonomic neuropathy usually affects several organs and functional systems like cardiovascular, digestion, temperature regulation, and sexual functions. The symptoms depend on the nerve affected, e.g., incomplete bladder emptying, stomach and bowel problems, orthostatic hypotension, or sweating. The presence of an autonomic neuropathy increases the risk of a cardiovascular crisis during exercise because patients with this condition may experience a silent ischemia without chest pain. An exercise program designed for type II diabetes with autonomic neuropathy should avoid exercise in hot and cold environments and should require adequate fluid replacement, as this usually influences thermoregulation [7, 34, 40]. In diabetic nephropathy, exercise intensity should be relatively low due to a potentially reduced overall exercise capacity.

The prevalence of diabetes retinopathy appears to vary with the age of onset and duration of the disease. Retinopathy lesions could be divided into two large categories: simple and proliferative. Part of the 10$18 \%$ of patients with simple retinopathy will eventually progress to the proliferative form within a 10-year period. About half of patients with proliferative retinopathy will become blind within 5 years $[8,17]$. Patients with active proliferative diabetes retinopathy,

Table 6 Major DM complications with clinical manifestations and exercise recommendations (adapted from the American Diabetes Association [7], Sigal et al. [40], Vinik et al. [45], and Wilmore and Costil [51])

\begin{tabular}{|c|c|c|}
\hline & Clinical manifestations & Exercise recommendation \\
\hline $\begin{array}{l}\text { Peripheral } \\
\text { neuropathy }\end{array}$ & $\begin{array}{l}\text { Numbness, tingling, coldness, burning pain, hypersensitivity } \\
\text { to touch }\end{array}$ & $\begin{array}{l}\text { Non-weight-bearing exercise such as } \\
\text { swimming, bicycling }\end{array}$ \\
\hline $\begin{array}{l}\text { Autonomic } \\
\text { neuropathy }\end{array}$ & $\begin{array}{l}\text { Incomplete bladder emptying, stomach and bowel problems, } \\
\text { orthostatic hypotension, sweating }\end{array}$ & $\begin{array}{l}\text { Exercise stress test is necessary before } \\
\text { starting an exercise program. }\end{array}$ \\
\hline $\begin{array}{l}\text { Diabetic } \\
\text { retinopathy }\end{array}$ & Scar tissue in the retina & $\begin{array}{l}\text { Contraindication in vigorous aerobic } \\
\text { and resistance exercise }\end{array}$ \\
\hline $\begin{array}{l}\text { Cardiovascular } \\
\text { disease }\end{array}$ & Occurrence of chest pain & Exercise stress test \\
\hline Hypertension & Blood pressure higher than $140 / 90 \mathrm{mmHg}$ & $\begin{array}{l}\text { Breathing technique during resistance } \\
\text { exercise should be trained }\end{array}$ \\
\hline Dyslipidemia & $\begin{array}{l}\text { Increased plasma levels of VLDL and TG, decreased plasma } \\
\text { level of HDL }\end{array}$ & Low intensity and prolonged exercise \\
\hline
\end{tabular}


who perform strenuous exercise, may provoke a vitreous hemorrhage or a traction retinal detachment. Therefore, such patients should avoid anaerobic exercise and physical activity that involves straining or Valsalva maneuvers, as in weightlifting. Exercise must be low-impact such as swimming, walking, and stationary cycling [7].

Cardiovascular disease is a major cause of mortality in persons with diabetes. Approximately, $85 \%$ of mortality in patients with type II diabetes is due to ischemic heart diseases. Silent heart attacks can occur in patients with DM because an autonomic neuropathy can mask the symptom of chest pain usually associated with myocardial ischemia [8, 34]. Hypertension, dyslipidemia, smoking, a family history of coronary disease, and the presence of micro- or macroalbuminuria also constitute risk factors [7, 51]. Graded exercise testing should be performed before the prescription of a training program.

Blood pressure higher than $140 / 90 \mathrm{mmHg}$ is a major risk factor for the development of cardiovascular diseases and microvascular complications that normally occur in over $60 \%$ of patients with type II diabetes. Hypertension is likely to be present as part of the metabolic syndrome. In general, physical exercise associated with a diet aimed at reduced sodium intake, reductions in bodyweight, avoidance of excessive alcohol consumption, and increasing activity levels have proven to be effective in reducing blood pressure $[7,14,51]$. Activities involving breath holding, such as heavy resistance training, should be avoided unless the patients have acquired a proper breathing technique during such an activity. When weightlifting, it is important to exhale during the most strenuous part of the exercise and to inhale during the least, so that excessive changes in blood pressure are less likely to occur.

The occurrence of dyslipidemia increases the risk factor of macrovascular diseases. In type II diabetes, dyslipidemia is characterized by enhanced plasma levels of triglyceride and also by decreased levels of high density lipoprotein (HDL). This profile is often called "diabetic dyslipidemia" [6]. Regular physical exercise can reduce the risk of developing a macrovascular disease by the improvement of the plasma lipid profile [10, 28]. In fact, regular exercise seems to be effective in reducing the level of triglycerides and VLDL, while increasing HDL. Within the lipid profile, LDL should be less than $130 \mathrm{mg} / \mathrm{dl}$, TG less than 200 $\mathrm{mg} / \mathrm{dl}$, and HDL more than $45 \mathrm{mg} / \mathrm{dl}$ [21]. The favorable reduction of triglycerides and lipoprotein cholesterol in patients with type II diabetes accompanies weight loss.
Low-intensity exercise, at least five times per week, $1 \mathrm{~h}$ per session, and performed continuously during 1 year, can reduce bodyweight. Weight loss also leads to a decrease in insulin resistance $[7,51]$.

Platelet dysfunction associated with dyslipidemia reveals a pattern of coagulation factors that increases coagulation, while on the other hand, decreases thrombolysis. In this case, platelet dysfunction could favor atherosclerosis and vascular thrombosis. Impairment in plasma fibrinolytic activity and tissue plasminogen activator activity, when plasminogen activator inhibitor-1 activity is increased, induces both thrombosis and defective dissolution of a clot once formed. Platelets in type II diabetes patients adhere to the endothelium because of insufficient generation of prostacyclin (PGI2) and nitric oxide (NO) by the vascular endothelium. Consequently, vasoconstriction and platelet aggregation could occur more rapidly than in healthy people. Insulin, by sensitizing the platelet to PGI2, is a natural antagonist of platelet hyperactivity, and in addition, it enhances the endothelial generation of PGI2 and NO. Thus, defects in insulin action in diabetes create a disordered platelet activity. Aspirin can block thromboxan synthesis by acetylation of the platelet cyclooxygenase and may be used to prevent cardiovascular disease in diabetic and nondiabetic patients $[3,45]$.

\section{Concluding remarks}

Aerobic exercise and resistance exercise are recommended for diabetic patients and must be individually adjusted to the physiological and metabolic limitations of each patient. Regular physical exercise and strength training encourage positive adaptations in the control of blood glucose concentration, insulin action, muscular strength, and exercise tolerance in patients with type II diabetes. However, to produce beneficial effects, exercise must be performed at a low intensity and duration (40-60\% $\mathrm{VO}_{2} \max$ for at least $150 \mathrm{~min} /$ week). Blood glucose should be monitored before and after exercise to prevent hypoglycemia. Fluid replacement is recommended before, during, and after exercise. On the other hand, before starting an exercise program, a medical examination is necessary to identify diabetes-related complications affecting cardiovascular function, which may be aggravated by an exercise program. Nevertheless, lifestyle modifications including diet control coupled with physical regular exercise are important for successfully achieving glycemic control. 


\section{References}

1. American Association of Clinical Endocrinologist and the American College of Endocrinology (2002) The American association of clinical endocrinologists medical guidelines for the management of diabetes mellitus: The AACE system of intensive diabetes self-management-2002 update. Endocr Pract 8(suppl 1):41-82

2. American College of Sports Medicine (2000) Exercise and type II diabetes. Med Sci Sports Exerc 32:1345-1360

3. American Diabetes Association (2004) Aspirin therapy in diabetes. Diabetes Care 27:S72-S73

4. American Diabetes Association (2004) Diabetes nutrition recommendation for health care institutions. Diabetes Care 27(suppl 1):S55-S57

5. American Diabetes Association (2004) Diagnosis and classification of diabetes mellitus. Diabetes Care 27(suppl 1): S5-S10

6. American Diabetes Association (2003) Management of dyslipidemia in adults with diabetes. Diabetes Care 26(suppl 1):S83-S86

7. American Diabetes Association (2004) Physical activity, exercise and diabetes. Diabetes Care 27(suppl 1):S58-S62

8. American Diabetes Association (2003) Standards of medical care for patients with diabetes mellitus. Diabetes Care 26(suppl):S33-S50

9. Barnard RJ, Jung T, Inkeles SB (1994) Diet and exercise in the treatment of NIDDM: The need for early emphasis. Diabetes Care 17:1469-1472

10. Carroll S, Dudfield M (2004) What is the relationship between exercise and metabolic abnormalities? A review of the metabolic syndrome. Sport Med 34:371-418

11. Chin-Wen H, Shin-Wei C, Hsin-Yi H, Wen-Chih L, ChingHung L, Chia-Hua K (2003) Interactive effect of exercise training and growth hormone administration on glucose tolerance and muscle GLUT4 protein expression in rats. J Biomed Sci 10:689-696

12. Conquering Diabetes in All of its Forms. http://www.Joslin. harvard.edu/education/library/lowbs_exercises.html

13. Daugaard JR, Richter EA (2001) Relationship between muscle fibre composition, glucose transport protein 4 , and exercise training: possible consequences in non-insulindependent diabetes mellitus. Acta Physiol Scand 171:267276

14. Eriksson J, Taimela S, Eriksson K, Parviainen S, Peltonen S, Kujala U (1997) Resistance training in the treatment of noninsulin-dependent diabetes mellitus. Int J Sports Med 18:242-246

15. Eriksson JG (1999) Exercise and the treatment of type 2 diabetes mellitus. Sports Med 27:381-391

16. Fletcher B, Gulanick M, Lamendola C (2002) Risk factors for type 2 diabetes mellitus. J Cardiovasc Nurs 16:17-23

17. Foster DW (1991) Diabetes mellitus. In: Wilson JD, Braunwald E, Isselbacher KJ, Petersdrof RG, Martin JB, Fauci AS, Root RK (eds) Harrison's principles of internal medicine, 12th edn. McGraw-Hill, New York, pp 1739-1758

18. Franz MJ, Holzmeister LA, Bantle JP, Hoogwerf B, Becbe CA, Mayer-Davis E, Brunzell JD, Mooradian AD, Chiasson J, Purnell JQ, Garg A, Wheeler M (2002) Evidence-based nutrition principles and recommendation for the treatment and prevention of diabetes and related complication. Diabetes Care 25:148-198

19. Gabir MM, Hanson RL, Babelea D, Imperatore G, Roumain J, Bennett PH, Knowler WC (2000) Plasma glucose and prediction of microvascular disease and mortality. Diabetes Care 23:1113-1118

20. Garg A (1998) High-monounsaturated fat diets for patients with diabetes mellitus: a meta-analysis. Am J Clin Nutr 67:577S-582S

21. Goldberg IJ (2001) Clinical review 124: diabetic dyslipidemia: causes and consequences. J Clin Endocrinol Metab 86:965-971

22. Goodyear LJ, Kahn BB (1998) Exercise, glucose transport, and insulin sensitivity. Annu Rev Med 49:235-261

23. Henriksen EJ (2002) Exercise effects of muscle insulin signaling and action invited review: effects of acute exercise and exercise training on insulin resistance. J Appl Physiol 93:788-796

24. Ivy JL (2004) Muscle insulin resistance amended with exercise training: role of GLUT4 expression. Med Sci Sports Exerc 36:1207-1211

25. Ivy JL (1997) Role of exercise training in the prevention and treatment of insulin resistance and non-insulin-dependent diabetes mellitus. Sports Med 24:321-336

26. Kennedy JW, Hirshman MF, Gernivo EV, Ocel JV, Forse RA, Hoenig SJ, Aronson D, Goodyear LJ, Horton ES (1999) Acute exercise induces GLUT4 translocation in skeleton muscle of normal human subjects and subjects with type 2 diabetes. Diabetes 48:1192-1197

27. Leith LM, Taylor AH (1992) Behavior modification and exercise adherence: alterative review. J Sport Behav 15: 60-75

28. Leutholtz BC, Ripoll I (1999) Diabetes. In: Wolinsky I (ed) CRC exercise and disease management. CRC Press, Boca Raton, FL, pp 21-36

29. Maiorana A, O’Driscoll G, Goodman C, Taylor R, Green D (2002) Combined aerobic and resistance exercise improves glycemic control and fitness in type 2 diabetes. Diabetes Res Clin Pract 56:115-123

30. Mayfield J (1998) Diagnosis and classification of diabetes mellitus: new criteria. Am Fam Physician 58:1355-1362

31. Murphy C, Simkins M, Helowicz R (1999) Diabetes exercise project. J Hum Nutr Diet 12(suppl 1):79-90

32. Östenson CG (2001) The pathophysiology of the type 2 diabetes mellitus: an overview. Acta Physiol Scand 171:241247

33. Payne C. Diabetes Mellitus. http://www.latrobe.edu.au/ podiatry/diabetesresources/diabetes_lecture_1

34. Peirce NS (1999) Diabetes and exercise. Br J Sports Med 33:161-173

35. Pigman HT, Gan DX, Krousel-wood MA (2002) Role of exercise for type 2 diabetes patient management. South Med J 95:72-77

36. Poirier P, Tremblay A, Broderick T, CatellierC, Tancrede G, Nadeau (2002) Impact of moderate aerobic exercise training on insulin sensitivity in type 2 diabetes men treated with oral hypoglycemic agents: is insulin sensitivity enhanced only nonobese subjects? Med Sci Mon 8:cr59-cr65

37. Powers SK, Howley ET (2004) Hormone response to exercise. In: Dorwick T (ed) Exercise physiology, 5th edn. McGraw Hill, pp 71-103

38. Ryder JW, Chibalin AV, Zierath JR (2001) Intracellular mechanisms underlying increases in glucose uptake in response to insulin or exercise in skeleton muscle. Acta Physiol Scand 171:249-257

39. Sacks DB, Bruns DE, Goldstein DE, MacLaren NK, McDonald JM, Parrot M (2002) Guidelines and recommendations for laboratory analysis in the diagnosis and management of diabetes mellitus. Diabetes Care 25:750-786 
40. Sigal RJ, Kenny GP, Wasserman DH, Castaneda-Sceppa C (2004) Physical activity/exercise and type 2 diabetes. Diabetes Care 27:2518-2539

41. Stratton IM, Adler AI, Neil HA, Mathews DR, Manley SE, Cull CA, Hadden D, Turner RC, Holman RR (2000) Association of glycemia with macro vascular and microvascular complications of type 2 diabetes (UKPDS35): prospective observational study. Br Med J 321:405-412

42. Tokmakidis SP, Zois CE, Volaklis KA, Kotsa K, Touvra AM (2004) The effects of a combined strength and aerobic exercise program on glucose control and insulin action in women with type 2 diabetes. Eur J Appl Physiol 92:437-442

43. UK Prospective Diabetes study (UKPDS) Group (1998) Effect of intensive blood glucose control with metformin on complications in overweight patients with type II diabetes (UKPDS34). Lancet 352:854-865

44. UK Prospective Diabetes study (UKPDS) Group (1998) Intensive blood glucose control with sulfonylureas or insulin compared with conventional treatment and risk of complication in patients with type II diabetes (UKPDS 33). Lancet 352:837-853

45. Vinik AI, Nolan R, Erbas T, Pittenger GL, Park TS (2001) Platelet dysfunction in type 2 diabetes. Diabetes Care 24:1476-1485
46. Wägner AM, Martinez-Rubio A, Ordóòez-Llanos J, PérezPérez A (2002) Diabetes mellitus and cardiovascular disease. Eur J Intern Med 13:15-30

47. Walker K, Piers L, Putt R, Jones J, O’Dea K (1999) Effects of regular walking on cardiovascular risk factors and body composition in normoglycaemic women and women with Type 2 diabetes. Diabetes Care 22:555-561

48. Wallberg-Henriksson H, Rincon J, Zierath JR (1998) Exercise in the management of non-insulin-dependent diabetes mellitus. Sports Med 25:25-35

49. Wasserman DH, Spalding JA, Lacy DB, Colburn CA, Goldstein RE, Cherrington AD (1989) Glucagon is a primary controller of hepatic glycogenolysis and gluconeogenesis during muscular work. Am J Physiol 257:E108 (Abstract)

50. Wild S, Sicree R, Roglic G, King H, Green A (2004) Global prevalence of diabetes; estimates for the years 2000 and projections for 2030. Diabetes Care 27:1047-1053

51. Wilmore JH, Costill DL (2004) Cardiovascular disease and physical activity. In: Wilmore JH (ed) Physiology of sports and exercise, 3rd edn. Human Kinetics, Champaign, IL, pp 639-661

52. Young JC (1995) Exercise prescription for individuals with metabolic disorders, Practical considerations. Sports Med 19:43-54 